\title{
REPLI-g X DNA
}

National Cancer Institute

\section{Source}

National Cancer Institute. REPLI-g X DNA. NCI Thesaurus. Code C156439.

A genomic DNA sample that has been produced by two rounds of REPLI-g amplification. 